\title{
Evaluation of exposure dose in fetal computed tomography using organ-effective modulation
}

\author{
Masanao Kobayashi $^{1}$ (1) $\cdot$ Tomonobu Haba $^{1} \cdot$ Sayaka Suzuki ${ }^{2} \cdot$ Yusei Nishihara $^{2} \cdot$ Yasuki Asada $^{1} \cdot$ Kazuyuki Minami $^{1}$
}

Received: 3 April 2020 / Accepted: 19 August 2020 / Published online: 14 September 2020

(c) The Author(s) 2020

\begin{abstract}
Organ-effective modulation (OEM) is a computed tomography scanning technique that reduces the exposure dose to organs at risk. Ultrasonography is commonly used for prenatal imaging, but its reliability is reported to be limited. Radiography and computed tomography (CT) are reliable but pose risk of radiation exposure to the pregnant woman and her fetus. Although there are many reports on the exposure dose associated with fetal CT scans, no reports exist on OEM use in fetal CT scans. We measured the basic characteristics of organ-effective modulation (X-ray output modulation angle, maximum X-ray output modulation rate, total X-ray output modulation rate, and noise modulation) and used them in a Monte Carlo simulation to evaluate the effect of this technique on fetal CT scans in terms of image quality and exposure dose to the pregnant woman and fetus. Using ImPACT MC software, Monte Carlo simulations of $\mathrm{OEM}_{\mathrm{ON}}$ and $\mathrm{OEM}_{\mathrm{OFF}}$ were run on 8 cases involving fetal CT scans. We confirmed that the organ-effective modulation X-ray output modulation angle was $160^{\circ}$; the X-ray output modulation rate increased with increasing tube current; and no modulation occurred at tube currents of $80 \mathrm{~mA}$ or below. Our findings suggest that OEM has only a minimal effect in reducing organ exposure in pregnant women; therefore, it should be used on the anterior side $\left(\mathrm{OEM}_{\mathrm{ON} \text {,front }}\right)$ to reduce the exposure dose to the fetus.
\end{abstract}

Keywords Organ-effective modulation $\cdot$ Fetal CT scan $\cdot$ Organ exposure $\cdot$ Monte Carlo simulation

Masanao Kobayashi

masa1121@fujita-hu.ac.jp

Tomonobu Haba

habatomo@fujita-hu.ac.jp

Sayaka Suzuki

sayaka.suzuki.cm@fujita-hu.ac.jp

Yusei Nishihara

yusei.nishihara@fujita-hu.ac.jp

Yasuki Asada

asada@fujita-hu.ac.jp

Kazuyuki Minami

kminami@fujita-hu.ac.jp

1 Graduate School of Medical Sciences, Fujita Health University, 1-98 Dengakugakubo, Kutsukake-cho, Toyoake, Aichi, Japan

2 Department of Radiology, Fujita Health University Hospital, 1-98 Dengakugakubo, Kutsukake-cho, Toyoake, Aichi, Japan

\section{Introduction}

Ultrasonography (US) is commonly used for prenatal image-based diagnosis of pregnancy [1-3], although opinion is divided on this matter, as some reports state that the reliability of US is limited by acoustic impedance [4, 5]. Radiography and computed tomography (CT) both demonstrate good diagnostic performance for the bone, but they are transmission-based techniques requiring radiation exposure to both the fetus and the pregnant woman. The exposure dose received by the fetus in these radiation-based diagnostic techniques is under $100 \mathrm{mGy}$, and it almost never increases the risk of prenatal death, deformity, or mental retardation by an amount detectable above spontaneous incidence [6]. ICRP Publication 84 mentions that detailed informed consent is required when the fetal exposure dose exceeds $1 \mathrm{mGy}$ and that methods of reducing exposure should be investigated when the fetus is exposed directly [6]. For these reasons, we should endeavor to reduce exposure through introduction of exposure-reducing techniques when using radiation in prenatal image-based diagnoses. 
Organ-effective modulation (OEM) is a recent development in the field of CT system scanning techniques that restricts X-ray output over specific tube orientations to reduce the exposure dose to organs at risk, such as the lens of the eye and the breast [7-9]. Many reports have evaluated the exposure dose in fetal CT scans [10-12], but no reports have used OEM in fetal CT scans and investigated the effects in detail. Moreover, the American College of Radiology and the Society for Pediatric Radiology have recommended the use of auto-exposure control techniques but have not discussed the possibility of reducing patient exposure with the recently developed OEM technique [13].

Herein, we investigated the potential clinical application of OEM in fetal CT scans by measuring the basic characteristics of OEM (X-ray output modulation angle, maximum $\mathrm{X}$-ray output modulation rate, total X-ray output modulation rate, and noise modulation) and using them to run a Monte Carlo (MC) simulation, thereby evaluating the effect of OEM on fetal CT scans in terms of image quality and exposure dose to the fetus and the pregnant woman.

\section{Methods}

\section{Evaluating the basic characteristics of OEM}

A 32-cm-diameter polymethyl methacrylate (PMMA) phantom was positioned with its center at the isocenter of the CT system (Aquilion ONE Vision Edition, Canon Medical Systems, Otawara, Japan). A solid-state detector (Piranha, RTI) was inserted at the center of the phantom and was scanned to obtain a dose rate profile (mGy/s) $[14,15]$. Volume scanning was performed at tube voltages of 80 and $100 \mathrm{kV}$, a 320-mm-diameter effective field-of-view, rotation speed of $500 \mathrm{~ms} /$ rot, slice width of $0.5 \mathrm{~mm} \times 320$, and $160-\mathrm{mm}$ scan range (160-mm width acquisition in a single non-helical rotation). For $\mathrm{OEM}_{\mathrm{OFF}}$, the tube current was set to "SD (standard deviation of image noise)." Table 1 shows the tube currents observed (values displayed on system console) after changing to $\mathrm{OEM}_{\mathrm{ON}}$ and the resulting decrease in X-ray output.

\section{X-ray output modulation angle}

The X-ray output modulation angle was calculated using Eq. 1 assuming a single rotation of a volume scan and modulation through $360^{\circ}$ at $0.5 \mathrm{~s} / \mathrm{rot}$, where $\theta$ is the X-ray output modulation angle $\left({ }^{\circ}\right), \mathrm{T}_{1 \text { rot }}$ is the time taken for a single rotation, and $\mathrm{T}_{\mathrm{drr}}$ is the dose rate reduction time (ms). $\mathrm{T}_{\mathrm{drr}}$ was obtained by comparing the dose rate profiles of $\mathrm{OEM}_{\mathrm{OFF}}$ and $\mathrm{OEM}_{\mathrm{ON}}$. However, due to variations at each of the plotted points forming the dose rate profiles, the start and finish times of dose rate reduction could not be measured accurately. For this reason, peaks before and after the start of dose rate reduction were identified, and the start and finish times were recorded when $1 \%$ modulation was observed relative to the peak value. In addition, the results for tube currents of 100,90 , and $80 \mathrm{~mA}$ were excluded for $\theta$ evaluation.

$\theta=360 \times \frac{1}{T_{1 \text { rot }}} \times \mathrm{T}_{d r r}$

\section{Maximum X-ray output modulation rate $\left(\mathrm{DM}_{\mathrm{Max}}\right)$ and total X-ray output modulation rate $\left(\mathrm{DM}_{\text {Total }}\right)$}

X-ray output modulation rate (DM) was calculated according to the dose rate profiles for $\mathrm{OEM}_{\mathrm{OFF}}$ and $\mathrm{OEM}_{\mathrm{ON}}$ using Eqs. 2 and 3:

$$
\begin{aligned}
& D M_{\text {Max }}=\left[1-\frac{D R_{O E M_{O N}^{M a x}}^{M a}}{D R_{O E M_{O F F}}}\right] \times 100 \\
& D M_{\text {Total }}=\left[1-\frac{D_{O E M_{O N}}^{\text {Total }}}{D_{\text {OEM }_{\text {OFF }}^{\text {Total }}}}\right] \times 100
\end{aligned}
$$

\begin{tabular}{|c|c|c|c|c|c|c|c|c|c|c|c|c|c|c|}
\hline Tube current ${ }^{\mathrm{a}}(\mathrm{mA})$ & 500 & 400 & 300 & 250 & 200 & 150 & 130 & 100 & 90 & 80 & 70 & 60 & 50 & 40 \\
\hline SD setting at $80 \mathrm{kV}^{\mathrm{b}}$ & 14.5 & 16.5 & 19.5 & 21.7 & 25.2 & 30.0 & 32.5 & 37.0 & 40.0 & 43.0 & 45.0 & 50.0 & 55.0 & 63.0 \\
\hline SD setting at $100 \mathrm{kV}^{\mathrm{b}}$ & 8.7 & 9.8 & 11.5 & 12.6 & 14.4 & 16.5 & 18.0 & 21.0 & 22.0 & 23.0 & 25.0 & 27.0 & 30.0 & 34.0 \\
\hline Tube current at $\mathrm{OEM}_{\mathrm{ON}}{ }^{\mathrm{c}}(\mathrm{mA})$ & 425 & 340 & 255 & 213 & 170 & 133 & 118 & 95 & 88 & 80 & 70 & 60 & 50 & 40 \\
\hline
\end{tabular}

Table 1 Changes in tube current between $\mathrm{OEM}_{\mathrm{OFF}}$ and $\mathrm{OEM}_{\mathrm{ON}}$

Tube voltage: $80 \mathrm{kV}$ and $100 \mathrm{kV}$, X-ray tube rotation speed: 0.5 s/rot, slice thickness: $0.5 \mathrm{~mm}$, slice width: $160 \mathrm{~mm}$, effective field-of-view: $320 \mathrm{~mm}$

${ }^{\mathrm{a}} \mathrm{OEM}_{\mathrm{OFF}}$ tube current

${ }^{\mathrm{b}} \mathrm{SD}$ setting required to adjust output at a given tube current

${ }^{\mathrm{c}}$ Tube current displayed on the control console during $\mathrm{OEM}_{\mathrm{ON}}$ relative to the tube current for $\mathrm{OEM}_{\mathrm{OFF}}$ as determined by the standard deviation of image noise (SD) setting at each tube voltage 
where $\mathrm{DM}_{\mathrm{Max}}$ is the maximum $\mathrm{X}$-ray output modulation rate $(\%), \mathrm{DR}_{\mathrm{Max}} \mathrm{OEM}_{\mathrm{ON}}$ is the dose rate with the greatest reduction after changing to $\mathrm{OEM}_{\mathrm{ON}}, \mathrm{DR}_{\mathrm{OEMOFF}}$ is the dose rate obtained with $\mathrm{OEM}_{\mathrm{OFF}}, \mathrm{DM}_{\text {Total }}$ is the total X-ray output modulation rate (\%), and $D_{O E M_{O N}}^{\text {Total }}$ and $D_{O E M_{O F F}}^{\text {Total }}$ are the total doses (mGy) during $\mathrm{OEM}_{\mathrm{ON}}$ and $\mathrm{OEM}_{\mathrm{OFF}}$, respectively.

\section{Image noise}

The solid-state detector was removed from the center of the PMMA phantom and replaced with a 1-cm-diameter PMMA cylinder. After scanning under the conditions described above, images were reconstructed with a slice thickness of $0.5 \mathrm{~mm}$ and a slice width of $0.5 \mathrm{~mm}$, after which image noise $\left(\mathrm{SD}_{\mathrm{ON} / \mathrm{OFF}}\right)$ was measured in 8 prescribed regions of interest (each $5.6 \mathrm{~cm}$ in diameter) per slice in 5 axial slices taken from the center of the reconstructed image, thereby yielding the percentage change in noise (n) (Fig. 1a).

$n=\left[\frac{S D_{O E M_{O N}}}{S D_{O E M_{O F F}}}-1\right] \times 100$

\section{Evaluated subjects}

Exposure dose was evaluated in 8 participants who underwent a fetal CT scan on the same CT system between 2010 and 2017 (3 cases of short extremities, 1 case of achondrogenesis, 1 case of thanatophoric dysplasia, 2 cases of other fetal disorders, and 1 case of threatened premature labor); the expectant mothers were aged $30 \pm 6$ years, had an abdominal circumference of $95 \pm 7.7 \mathrm{~cm}$, were weighing $62 \pm 4.7 \mathrm{~kg}$, and were at $32 \pm 2$ gestational weeks.

\section{ImPACT MC software}

ImPACT MC Version 1.60 (CT imaging GmbH, Erlangen, Germany) MC simulation software is capable of evaluating, based on photon interactions, the absorbed dose per individual voxel in DICOM images obtained by CT. The software program can process data such as bowtie filters, air kerma, energy spectra, CT-to-density conversion factor, and scanning conditions $[16,17]$. The data needed to run the MC simulation were measured based on the tube voltage, effective field of view, and other conditions used in the fetal CT scans.

\section{Measuring bowtie filter shape}

A free-in-air pencil ionization chamber (10X-3CT, Radcal Corp., Monrovia, CA, USA) was positioned at the isocenter of the CT system. The ionization chamber was moved in $10-\mathrm{mm}$ increments up to $180 \mathrm{~mm}$ from the isocenter along the $\mathrm{x}$-axis direction, and air kerma was measured at each step using an ionization chamber dosimeter (Model 9015, Radcal Corp., Monrovia, CA, USA) (Fig. 1b). To perform these measurements, the X-ray tube had to be fixed in the 12 o'clock position using "service mode." The percentage

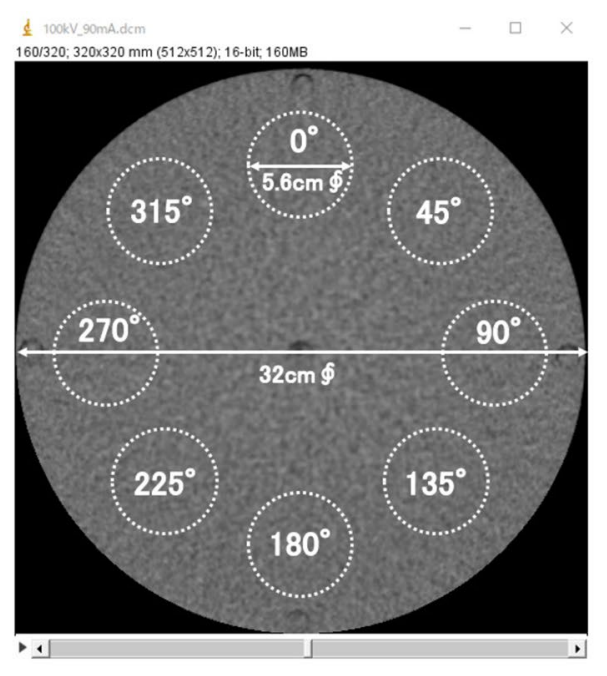

A

Fig. 1 Geometric arrangement used in experiments. a Measurement of image noise: Images were reconstructed with $0.5-\mathrm{mm}$ slice thickness and $0.5-\mathrm{mm}$ slice width; the 5 middle slices were chosen; 8 regions of interest $(5.6 \mathrm{~cm}$ diameter) were positioned on each slide image; and image noise $\left(\mathrm{SD}_{\mathrm{ON} / \mathrm{OFF}}\right)$ was measured in those regions. b

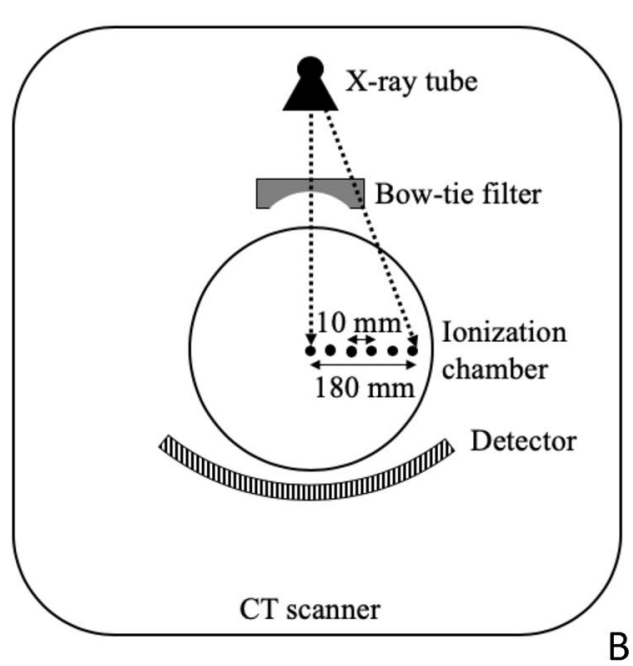

Bowtie filter shape evaluation: An ionization chamber was moved in 10 -mm increments up to $180 \mathrm{~mm}$ from the isocenter along the $\mathrm{x}$-axis and air kerma was measured at each step. To perform these measurements, the X-ray tube needed to be fixed in the 12 o'clock direction using "service mode" 
reduction in air kerma observed in these measurements was then used as the virtual bowtie filter in MC simulations.

\section{Measurement of air kerma and half-value layer and estimation of energy spectra}

After positioning the free-in-air pencil ionization chamber at the isocenter of the CT system, air kerma was measured per scan rotation using an ionization chamber dosimeter (accuracy: $\pm 4 \%$ ). Next, the solid-state detector (Black Piranha, RTI group AB, Mölndal, Sweden; 133 mm $\mathrm{H} \times 75 \mathrm{~mm} \mathrm{~W} \times 26 \mathrm{~mm} \mathrm{D}$ ) was placed on the system bed and the half-value layer was measured (accuracy: $\pm 10 \%$ or $2 \mathrm{~mm}$ ) [18]. X-rays oblique to the orientation of rotation that fell outside a 10-mm length detector area were screened by covering with a $3-\mathrm{mm}$ thick lead $(99.9 \%)$ case (Acrobio Corp., Tokyo, Japan; $147 \mathrm{~mm} \mathrm{H} \times 105 \mathrm{~mm} \mathrm{~W} \times 58 \mathrm{~mm} \mathrm{D}$ ). Energy spectra corresponding to the measured half-value layer were then estimated using the ImPACT MC spectra creation tool (based on the estimation method used by Tucker et al. [19]).

\section{CT value-to-density conversion}

Although the DICOM images obtained from CT scans contain $\mathrm{CT}$ values, the $\mathrm{MC}$ method requires a density value for each voxel. CT values were converted to density values using a standard conversion graph in the software program that was created from the CT values of water $(0 \mathrm{HU}: 1 \mathrm{~g} /$ $\mathrm{cm}^{2}$ ) and air (-1000 HU: $\left.0 \mathrm{~g} / \mathrm{cm}^{2}\right)$.

\section{MC simulation conditions}

Table 2 shows the scanning conditions used in the actual clinical fetal CT scans with $\mathrm{OEM}_{\mathrm{OFF}}$. Next, the DM for
$\mathrm{OEM}_{\mathrm{ON}}$ was estimated by linear approximation based on the relationships among the basic characteristics of OEM (Table 1). The tube current during $\mathrm{OEM}_{\mathrm{ON} \text {,front, }}$ which reduced the absorbed dose on the anterior side, and $\mathrm{OEM}_{\mathrm{ON}, \text { back}}$, which reduced the absorbed dose on the posterior side, modulated $\mathrm{DM}_{\mathrm{Max}}$ and $\mathrm{DM}_{\text {Total }}$ at the obtained $\theta$ values (see Sect. 3.1.1). MC simulations were then run with these scanning conditions; the mean dose absorbed by the organs and tissues $\left(\mathrm{D}_{\mathrm{T}, \mathrm{R}}\right)$ was measured based on the resulting absorbed dose distribution, and the effective dose (ED) was calculated.

\section{Evaluating exposure dose}

\section{Mean dose absorbed by organs and tissues $\left(D_{T, R}\right)$}

$\mathrm{D}_{\mathrm{T}, \mathrm{R}}$ (mGy) measurements were obtained by choosing around 3 regions of interest in each organ in DICOM images, depending on organ size. To determine full-body exposure to the fetus, where possible, we obtained measurements from the organs and tissues required to evaluate the ED. However, when an organ could not be discerned due to the low contrast of the DICOM images and small organ size, regions of interest were positioned based on anatomical relationships. The $\mathrm{D}_{\mathrm{T}, \mathrm{R}}$ of red bone marrow and mineralized bone was calculated using the evaluation method described by Nishizawa et al. [20] and reference data (Table 4.2 and Table A 1) [21] shown in ICRP Publication 110 used in constructing a reference person. As the pregnant woman receives exposure to only the abdominal region, five abdominal organs were selected for measurement (liver, kidneys, colon, uterus, and bladder). However, when any of these organs were outside the scanned area, the organ was excluded from evaluation.

Table 2 MC simulation conditions based on imaging conditions used in clinical examinations

\begin{tabular}{|c|c|c|c|c|c|c|c|c|c|}
\hline No. & $\begin{array}{l}\text { Tube } \\
\text { voltage } \\
(\mathrm{kV})\end{array}$ & Scan & $\begin{array}{l}\text { Slice } \\
\text { width } \\
(\mathrm{mm})\end{array}$ & $\begin{array}{l}\text { Field } \\
\text { of view } \\
(\mathrm{mm})\end{array}$ & $\begin{array}{l}\text { Tube current } 1 \\
\mathrm{OEM}_{\mathrm{OFF}} / \mathrm{OEM}_{\mathrm{ON}}{ }^{\mathrm{a}} \\
(\mathrm{mA})\end{array}$ & $\begin{array}{l}\text { Tube current } \\
2 \mathrm{OEM}_{\mathrm{OFF}} / \\
\mathrm{OEM}_{\mathrm{ON}}{ }^{\mathrm{a}} \\
(\mathrm{mA})\end{array}$ & $\begin{array}{l}\text { Tube current } \\
3 \mathrm{OEM}_{\mathrm{OFF}} / \\
\mathrm{OEM}_{\mathrm{ON}}{ }^{\mathrm{a}} \\
(\mathrm{mA})\end{array}$ & $\begin{array}{l}\text { Scan rotation } \\
\text { time }(\mathrm{sec} / \mathrm{rot})\end{array}$ & $\begin{array}{l}\text { Air kerma }^{\mathrm{b}} \\
(\mathrm{mGy} / 100 \mathrm{mAs})\end{array}$ \\
\hline A & 80 & 3 & 160 & 320 & $220 / 187$ & $220 / 187$ & $220 / 187$ & 0.5 & 11.17 \\
\hline B & 80 & 3 & 160 & 320 & $172 / 149$ & $217 / 185$ & $202 / 172$ & 0.5 & 11.17 \\
\hline $\mathrm{C}$ & 80 & 3 & 140 & 320 & $157 / 138$ & $217 / 185$ & $232 / 198$ & 0.5 & 11.17 \\
\hline D & 100 & 3 & 120 & 360 & $110 / 103$ & $120 / 110$ & $110 / 103$ & 0.5 & 19.11 \\
\hline $\mathrm{E}$ & 100 & 3 & 120 & 320 & $100 / 95$ & $110 / 103$ & $105 / 99$ & 0.5 & 19.08 \\
\hline $\mathrm{F}$ & 100 & 3 & 128 & 320 & $115 / 107$ & $145 / 129$ & $125 / 114$ & 0.5 & 19.08 \\
\hline G & 100 & 2 & 160 & 320 & $85 / 84$ & $105 / 99$ & & 0.5 & 19.08 \\
\hline $\mathrm{H}$ & 100 & 3 & 140 & 320 & $80 / 80$ & $90 / 88$ & $85 / 84$ & 0.5 & 19.08 \\
\hline
\end{tabular}

${ }^{\mathrm{a}} \mathrm{OEM}_{\mathrm{ON}}$ tube current was estimated by linear approximation from the results in Table 1

${ }^{\mathrm{b}}$ Air kerma data are actual measurements 


\section{Effective dose (ED)}

ICRP Publication 103 [22] defines ED as a value calculated for an adult reference person and that ED is unrelated to body type, age, or sex. ICRP Publication 103 also mentions that ED should not be used to evaluate exposure dose to individuals. Given that this study specifically evaluates pregnant women and fetuses and verifies the effects of OEM per patient, we chose to evaluate the effect of OEM using $\operatorname{ED}(\mathrm{Sv})$, a parameter that goes beyond the scope of the prescribed definition of ED.

$E D=\sum_{T} W_{T} \sum_{R} W_{R} D_{T, R}$

where $\mathrm{W}_{\mathrm{T}}$ is the tissue weighting factor (ICRP Publication 103 [22]) and $\mathrm{W}_{\mathrm{R}}$ is the radiation weighting coefficient (1.0). We verified the effect of OEM on fetal CT scans based on the above parameters. This has been approved by the Institutional Review Board (HM18-433).

\section{Results}

\section{Basic characteristics of OEM}

\section{X-ray output modulation angle $(\theta)$}

An X-ray tube rotation speed of $500 \mathrm{~ms} /$ rot shows that a single rotation requires $500 \mathrm{~ms}$. The $\mathrm{OEM}_{\mathrm{OFF}}$ and $\mathrm{OEM}_{\mathrm{ON}}$ dose rate profiles were measured at this rotation speed. Figure $2 \mathrm{a}$ and $\mathrm{b}$ shows the dose rate profile for $\mathrm{OEM}_{\mathrm{OFF}}$ at an $80-\mathrm{kV}$ tube voltage and 90-mA tube current $\left(\mathrm{OEM}_{\mathrm{ON}}: 88 \mathrm{~mA}\right)$, showing modulation at a small proportion of dose rate, and the dose rate profile for $\mathrm{OEM}_{\mathrm{OFF}}$ at an $80-\mathrm{kV}$ tube voltage and 500-mA tube current $\left(\mathrm{OEM}_{\mathrm{ON}}: 425 \mathrm{~mA}\right)$, showing modulation at a markedly large proportion of dose rate. Based on the dose rate profiles, the X-ray output time from start-up to shutdown was $527.8 \pm 4.0 \mathrm{~ms}$. Assuming a rotation speed of $525 \mathrm{~ms}$, the X-ray tube rotated through $0.686^{\circ}$ every $1 \mathrm{~ms}$ $\left(360^{\circ} / 525 \mathrm{~ms}\right)$ and, therefore, $\mathrm{OEM}_{\mathrm{ON}} \theta=160.1 \pm 3.5^{\circ}$. At $100 \mathrm{kV}$ and $130 \mathrm{~mA}$, the angle $\theta$ was $136.5^{\circ}$, which was much smaller than all other angles and was excluded from evaluation as an outlier.
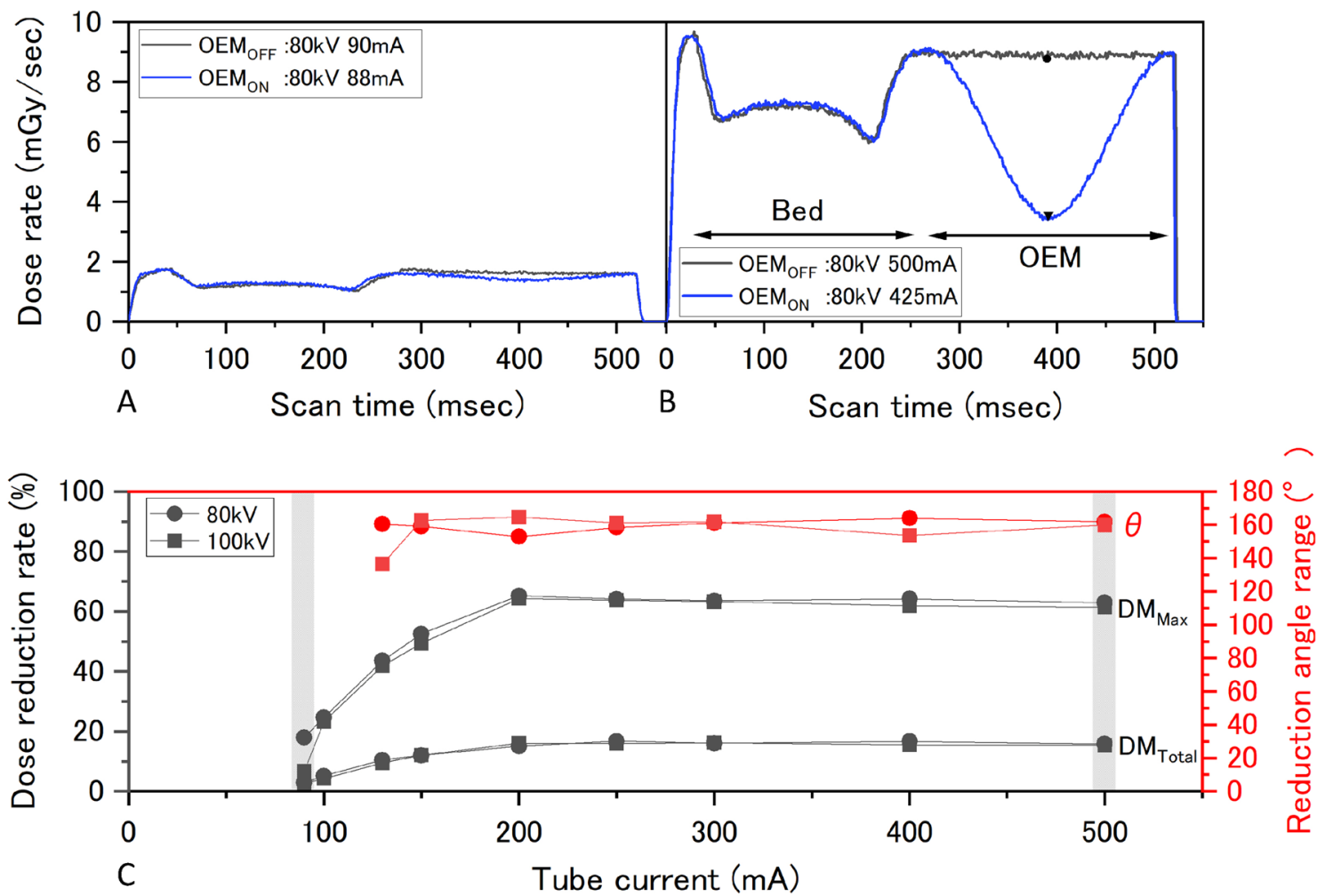

Fig. 2 Evaluating basic characteristics of OEM. a Dose rate profile at $80-\mathrm{kV}$ tube voltage and $90 \mathrm{~mA}$ tube current $\left(\mathrm{OEM}_{\mathrm{ON}}: 88 \mathrm{~mA}\right)$ for $\mathrm{OEM}_{\mathrm{OFF}}$ showing modulation of a small proportion of dose rate. b Dose rate profile at $80-\mathrm{kV}$ tube voltage and $500 \mathrm{~mA}$ tube current $\left(\mathrm{OEM}_{\mathrm{ON}}: 425 \mathrm{~mA}\right)$ for $\mathrm{OEM}_{\mathrm{OFF}}$ showing modulation of a markedly large proportion of dose rate. c Change in X-ray output modulation angle $(\theta)$, maximum $\mathrm{X}$-ray output modulation rate $\left(\mathrm{DM}_{\mathrm{Max}}\right)$, and total $\mathrm{X}$-ray output modulation rate $\left(\mathrm{DM}_{\text {Total }}\right)$ relative to tube current. The gray areas show the results from scanning conditions used in $\mathrm{A}$ and $\mathrm{B}$, respectively 
Maximum X-ray output modulation rate $\left(\mathrm{DM}_{\mathrm{Max}}\right)$ and total $X$-ray output modulation rate $\left(\mathrm{DM}_{\text {Total }}\right)$

$\mathrm{DM}_{\text {Max }}$ showed a dose reduction of $63.5 \% \pm 1.1 \%$ at $200 \mathrm{~mA}$ and higher, independent of tube voltage. Similarly, $\mathrm{DM}_{\text {Total }}$ showed a dose reduction of $16.0 \% \pm 0.5 \%$ at $200 \mathrm{~mA}$ and higher, independent of tube voltage. In addition, both $\mathrm{DM}_{\mathrm{Max}}$ and $\mathrm{DM}_{\text {Total }}$ gradually reduced in size below $200 \mathrm{~mA}$, and modulation was absent below $80 \mathrm{~mA}$. DM data taken from dose rate profiles for $90 \mathrm{~mA}$ and $500 \mathrm{~mA}$ tube currents are highlighted in gray in Fig. 2c. Dose rate profiles also allowed us to verify the effect of X-ray absorption by the bed.

\section{Image noise}

Figure 3 shows SD plotted on polar coordinates during $\mathrm{OEM}_{\mathrm{ON}}$ and $\mathrm{OEM}_{\mathrm{OFF}}$ for three representative scanning conditions. These three scanning conditions show characteristic image noise measurements obtained from the phantom. Considering the change in noise evaluated based on SD, there was no difference in $\mathrm{n}$ between $\mathrm{OEM}_{\mathrm{ON}}$ and $\mathrm{OEM}_{\mathrm{OFF}}$ in any angular direction for an $80 \mathrm{kV}$ tube with a current of $90 \mathrm{~mA}$ that exhibits low DM. At a tube current of $500 \mathrm{~mA}$, in the $0^{\circ} \pm 90^{\circ}$ range where there were concerns over the effect of OEM, we observed an increase of $6.0 \% \pm 2.4 \%$. Similarly, the change in useful X-ray output in fetal CT scans was $3.2 \% \pm 3.3 \%$ at $400 \mathrm{~mA}, 2.4 \% \pm 1.0 \%$ at $300 \mathrm{~mA}$, and $-0.5 \% \pm 2.5 \%$ at $250 \mathrm{~mA}$, showing that the smaller the $\mathrm{DM}$, the smaller the effect on $\mathrm{n}$. In contrast, in the $180^{\circ} \pm 90^{\circ}$ range, the change was $3.4 \% \pm 2.5 \%$ at $500 \mathrm{~mA}, 1.9 \% \pm 1.1 \%$ at $400 \mathrm{~mA}$, and $1.4 \% \pm 2.0 \%$ and $0.3 \% \pm 0.8 \%$ at 300 and $250 \mathrm{~mA}$, respectively, showing a smaller effect on $\mathrm{n}$ compared to that of the $0^{\circ} \pm 90^{\circ}$ range. The greatest effect on $n$ was $7.8 \%$ at $500 \mathrm{~mA}$ in the $270^{\circ}$ direction. For a tube voltage of $100 \mathrm{kV}$, at a tube current of $500 \mathrm{~mA}$, the effect on $\mathrm{n}$ in the $0^{\circ} \pm 90^{\circ}$ range was $-1.9 \% \pm 2.1 \%$ and that in the $180^{\circ} \pm 90^{\circ}$ range was $0.7 \% \pm 2.0 \%$, indicating no effect of OEM and implying a difference caused by tube voltage (Fig. 3).

\section{ImPACT MC}

\section{Bowtie filter shape}

Air kerma, which was measured in the $\mathrm{x}$-axis direction, became smaller the further it was measured from the isocenter (Fig. 4a). A bowtie filter that produces this reduction in air kerma is bilaterally symmetrical around the central axis of the isocenter $(0 \mathrm{~mm})$; hence, the CT system used in $\mathrm{MC}$ simulations was equipped with a bowtie filter.

\section{Air kerma, half-value layer, and energy spectra}

For the 320-mm effective field-of-view commonly used in CT scans, at a tube voltage of $80 \mathrm{kV}$, the air kerma was $11.17 \mathrm{mGy} / 100 \mathrm{mAs}$, and at $100 \mathrm{kV}$, the air kerma was $19.08 \mathrm{mGy} / 100 \mathrm{mAs}$ (Table 2). Figure 4b shows energy spectra that correspond to half-value layers of $4.76 \mathrm{mmAl}$ $(40.9 \mathrm{keV})$ and $6.03 \mathrm{mmAl}(46.4 \mathrm{keV})$ for each tube voltage and were measured based on a 320-mm effective field-ofview size. The energy spectra show tungsten-specific X-rays with values of $59 \mathrm{keV}, 61 \mathrm{keV}, 67 \mathrm{keV}$, and $69 \mathrm{keV}$ (Ko1: $59.32 \mathrm{keV}, \mathrm{K} \alpha 2$ : $57.98 \mathrm{keV}, \mathrm{K} \beta 1: 67.24 \mathrm{keV}$, and $\mathrm{K} \beta 2$ : $67.42 \mathrm{keV}$, respectively).

\section{Evaluating exposure dose}

OEM scan conditions $\left(\theta=160^{\circ}\right)$ that produced a large DM in fetal CT scans were $\mathrm{OEM}_{\mathrm{ON} \text {,front }}$ and $\mathrm{OEM}_{\mathrm{ON} \text {,back }}$ (Figs. 5, 6). The results indicated that OEM produced a greater reduction in $\mathrm{D}_{\mathrm{T}, \mathrm{R}}$ in the thoraco-abdominal region than in the head and neck region, although OEM did not reduce $\mathrm{D}_{\mathrm{T}, \mathrm{R}}$ for specific organs in the thoraco-abdominal region. Further, $\mathrm{D}_{\text {redmarrow }}$
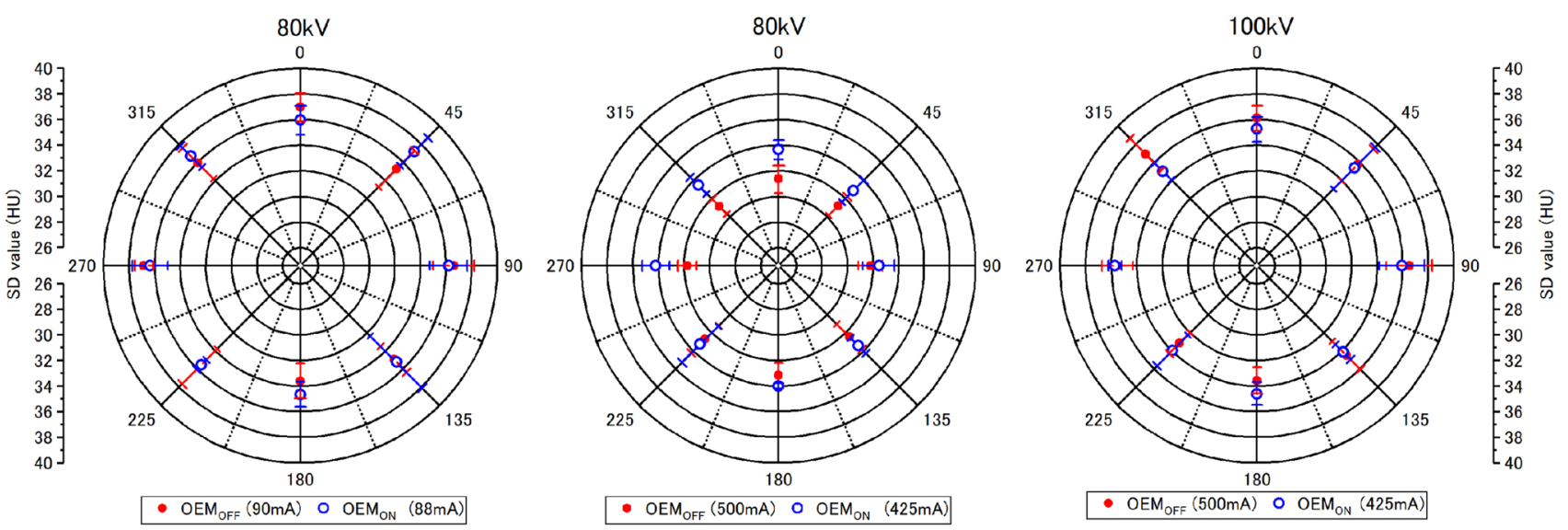

Fig. 3 OEM effect on image noise. The effect of OEM on image noise was evaluated in terms of changes in tube current and tube voltage 

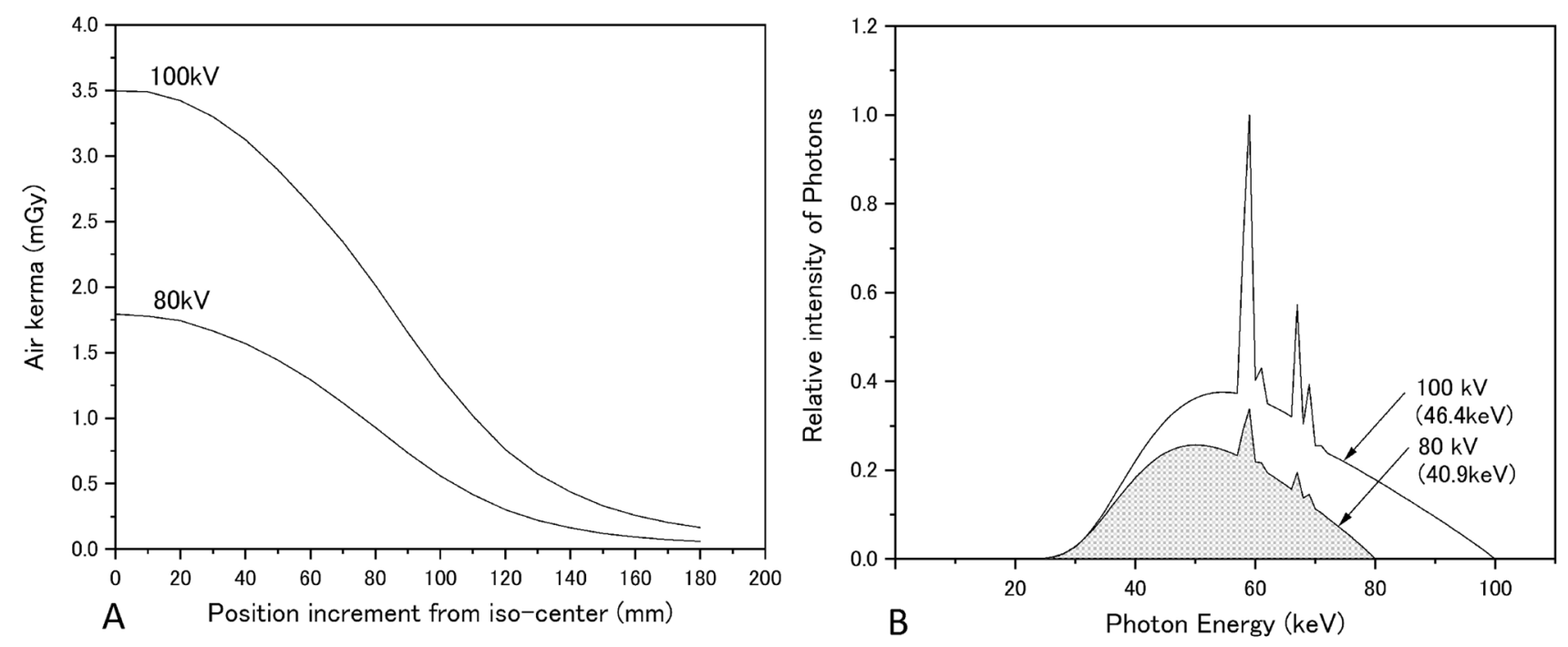

Fig. 4 Basic data used in MC simulations. a Bowtie shapes. b Energy spectra

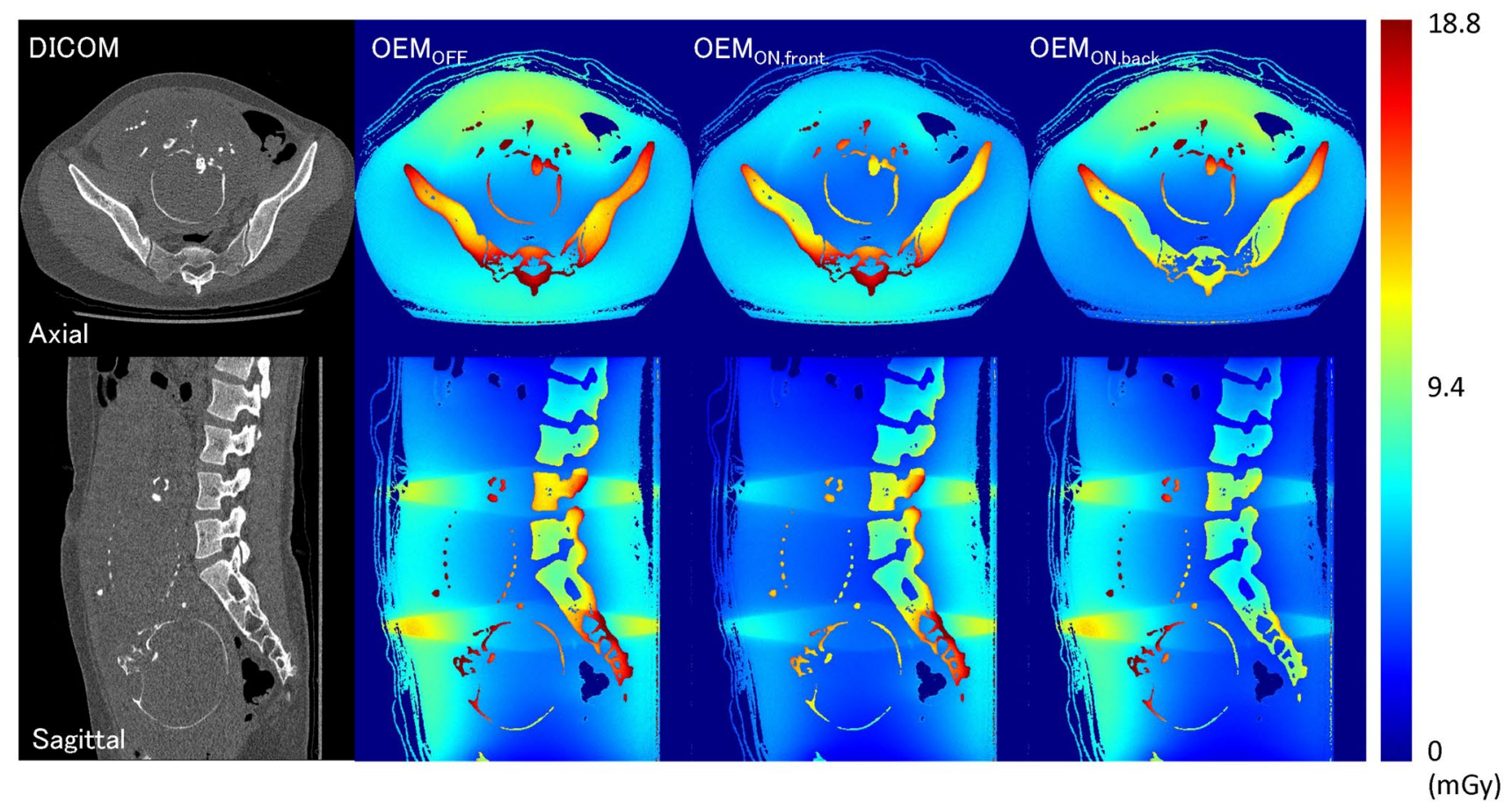

Fig. 5 Absorbed dose profiles obtained by MS simulation

was the highest absorbed dose in all fetuses. For $\mathrm{D}_{\mathrm{T}, \mathrm{R}}$ and ED where DM was large at a tube voltage of $80 \mathrm{kV}$, the dose to the fetuses scanned at this voltage (patients $\mathrm{A}-\mathrm{C}$, OEM $_{\mathrm{OFF}}: 6.6 \pm 0.4 \mathrm{mSv}, \mathrm{OEM}_{\mathrm{ON} \text {,front }}: 5.2 \pm 0.1 \mathrm{mSv}$ ) was reduced by $1.4 \mathrm{mSv}(27 \%)$, which was larger than the $0.5 \mathrm{mSv}(9 \%)$ reduction observed at $100 \mathrm{kV}$ (patients $\mathrm{D}-\mathrm{H}$, $\mathrm{OEM}_{\mathrm{OFF}}: 5.8 \pm 0.9 \mathrm{mSv}, \mathrm{OEM}_{\mathrm{ON}, \text { front }}: 5.3 \pm 0.6 \mathrm{mSv}$ ). A dose reduction was also observed with $\mathrm{OEM}_{\mathrm{ON}, \text { back }}$ (patients $\mathrm{A}-\mathrm{C}$ :
$6.1 \pm 0.6 \mathrm{mSv}$ [8\%], patients D-H: $5.7 \pm 0.8 \mathrm{mSv}$ [2\%]), but the reduction was not as large, as the $\mathrm{OEM}_{\mathrm{ON} \text {,front }}$ and $\mathrm{D}_{\mathrm{T}, \mathrm{R}}$ reductions were absent in specific organs.

For pregnant women, $\mathrm{D}_{T, \mathrm{R}}$ was evaluated in the liver, bladder, and colon when these organs appeared in DICOM images (Fig. 7). $\mathrm{D}_{\text {colon }}$ for $\mathrm{OEM}_{\mathrm{OFF}}$ was $0.55 \pm 0.10 \mathrm{mGy}$, that for $\mathrm{OEM}_{\mathrm{ON}, \text { front }}$ was $0.53 \pm 0.09 \mathrm{mGy}(4 \%)$, and that for $\mathrm{OEM}_{\mathrm{ON}, \text { back }}$ was $0.51 \pm 0.10 \mathrm{mGy}(8 \%)$, showing a very 


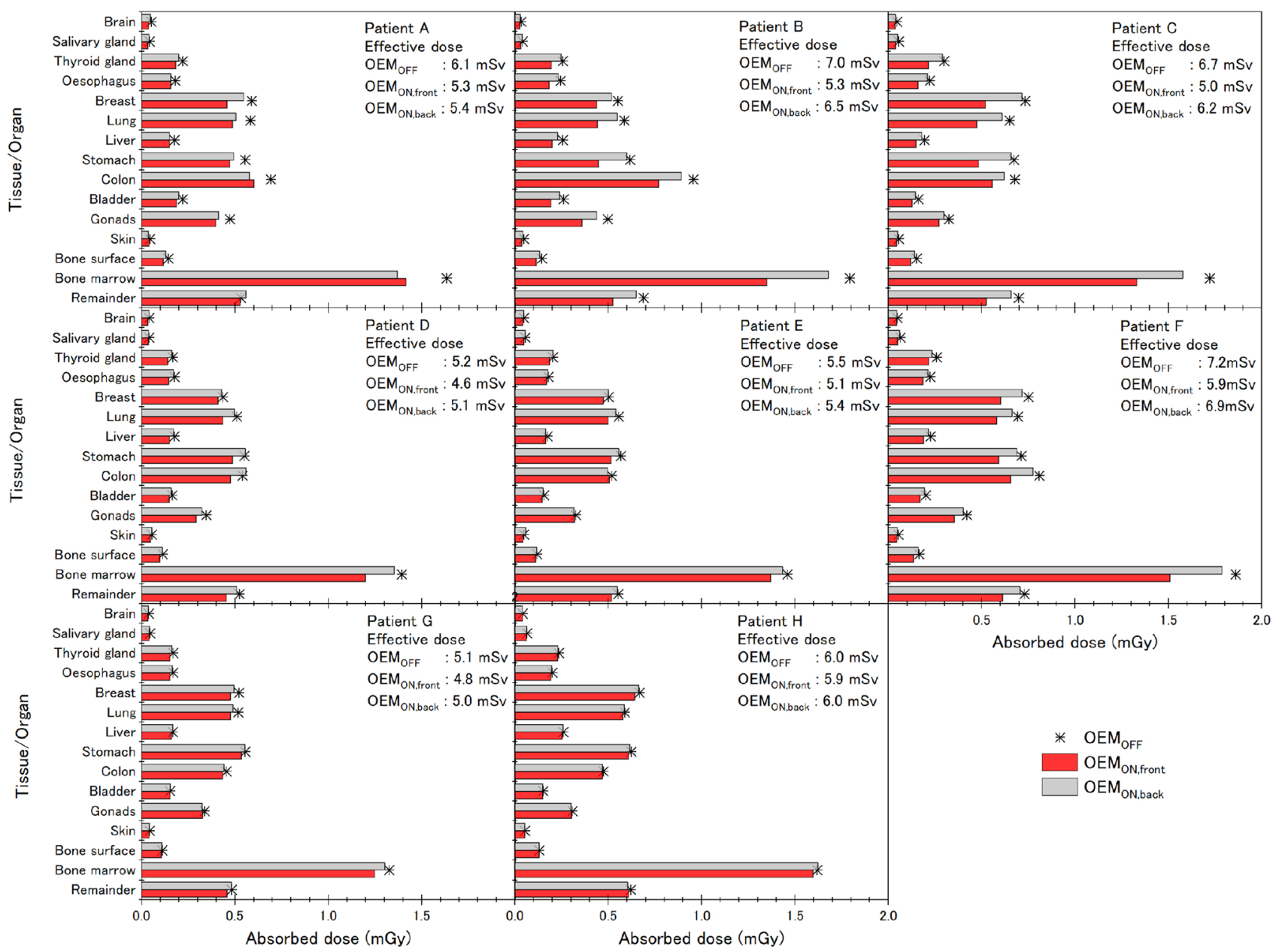

Fig. 6 Comparison of dose absorbed by fetus organs and tissues $\left(\mathrm{D}_{\mathrm{T}, \mathrm{R}}\right)$ and effective dose (ED). Fetal CT scans of patients A-H simulated using the scanning conditions shown in Table 2

slightly larger dose reduction with $\mathrm{OEM}_{\mathrm{ON}, \mathrm{back}}$. These results indicated that the dose reduction achieved using OEM was not as large in pregnant women as in fetuses.

\section{Discussion}

We measured the basic characteristics of OEM and ran MC simulations with these data to evaluate the effect of OEM on fetal CT scans in terms of image quality and exposure dose to the fetus and pregnant woman. This evaluation indicated that OEM was effective at reducing the exposure dose to the fetus but did not have a substantial effect on the exposure dose to pregnant women. Accordingly, we intend to actively implement dose reduction only for the fetus by modulating $\mathrm{X}$-ray output with $\mathrm{OEM}_{\mathrm{ON} \text {,front }}$ Given that $\mathrm{DM}$ increases at higher tube currents, $\mathrm{DM}$ is absent at $80 \mathrm{~mA}$ or below, and that $\mathrm{n}$ is higher in the $0^{\circ} \pm 90^{\circ}$ range at a tube voltage of $80 \mathrm{kV}$ but this difference is absent at $100 \mathrm{kV}$, these tube current characteristics and image quality characteristics must be considered when setting scanning conditions for $\mathrm{OEM}_{\mathrm{ON}, \text { front }}$.

Measurements revealed that the $\mathrm{T}_{1 \mathrm{rot}}$ of the CT system was approximately $25 \mathrm{~ms}$ longer than the $500-\mathrm{ms}$ set value. Part of this extra time is needed for the X-ray output to stabilize (start-up) and is handled as exposure not used for image reconstruction, and it results in a region of overlapping X-ray output. There are no findings that support attributing this region solely to start-up time, and the possibility cannot be ruled out that short periods of overlap will continue to occur after stabilization of X-ray output. To evaluate $\theta, T_{1 \text { rot }}$ was taken as the time from start-up to shutdown. The $\theta=160^{\circ}$ finding was obtained by using $\mathrm{T}_{1 \mathrm{rot}}=500 \mathrm{~ms}$ and did not include X-ray tube rotation time characteristics. Shorter rotation times are expected to make control of $\theta$ more difficult; thus, using shorter rotation times will require separate evaluation of $\theta$. As such, the X-ray output start-up cannot be easily recreated by an MC method; hence, it was not incorporated 


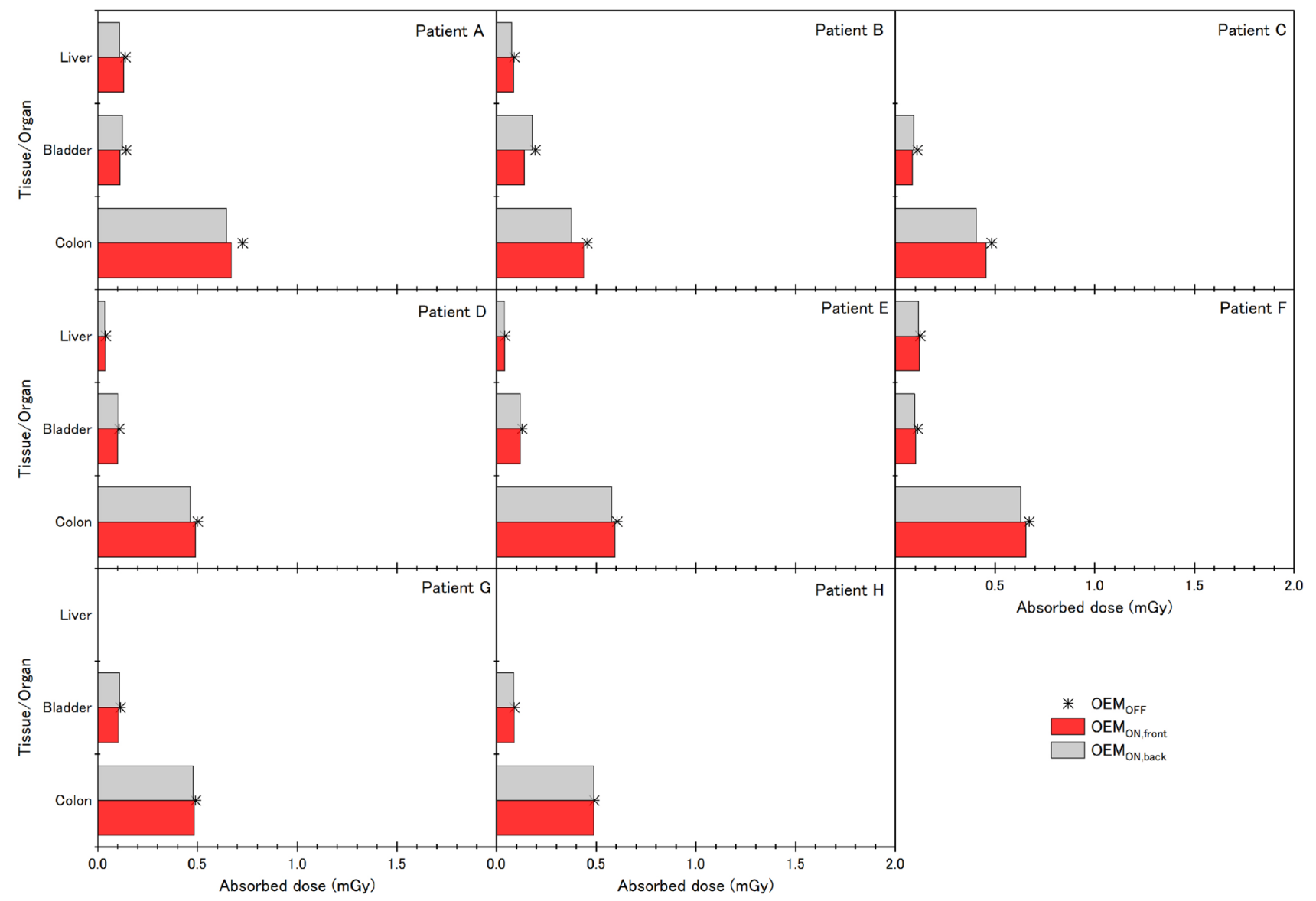

Fig. 7 Comparison of doses absorbed by organs and tissues of pregnant women $\left(\mathrm{D}_{\mathrm{T}, \mathrm{R}}\right)$. Fetal CT scans of patients $\mathrm{A}-\mathrm{H}$ simulated using the scanning conditions shown in Table 2 . In patients $\mathrm{C}, \mathrm{G}$, and $\mathrm{H}$,

into the MC simulations. Moreover, $\theta$ decreased to $136.5^{\circ}$ at a tube voltage of $100 \mathrm{kV}$ and a tube current of $130 \mathrm{~mA}$. This reduction was caused by measurements taken from a dose rate profile of a scan that ended while DM was still ongoing. Normally, when scanning is performed without orbital synchronization, the X-ray tube starts scanning from a random angle. Depending on the X-ray tube angle at which scanning begins, the scan may end while $\mathrm{X}$-ray output modulation is ongoing, or the X-ray output may not be modulated. This is not a major problem for helical scans, as DM is not implemented during the first rotation and X-ray output is modulated only in the appropriate angular range during subsequent successive rotations [23]. However, volume scanning acquires a wide slice thickness in only a single rotation; thus, any issue that prevents $\mathrm{X}$-ray output modulation during this rotation is unacceptable. This also applies to wide-volume scanning that involves consecutive volume scans.

OEM started modulating X-ray output at tube currents of $90 \mathrm{~mA}$ and above independent of tube voltage. The modulation rate in terms of $\mathrm{DM}_{\mathrm{Max}}$ and $\mathrm{DM}_{\text {Total }}$ was also constant the liver of the pregnant woman was outside the scanning range and did not appear in the DICOM image; hence, dose values for the liver are not shown

at tube currents of $200 \mathrm{~mA}$ and above. Accordingly, OEM is not expected to be effective at low tube currents, below $90 \mathrm{~mA}$, but at tube currents of $200 \mathrm{~mA}$ and higher, the behavior mentioned above will produce a dose-reducing effect. Given these findings, when the objective is to reduce the exposure dose, we propose selecting a low tube voltage in the scan settings to obtain high tube currents.

In contrast, when OEM was used at high tube currents, the results indicated that $\mathrm{n}$ increases in the $0^{\circ} \pm 90^{\circ}$ range together with substantial DM. When the objective is to avoid reducing image quality due to image noise, when the tube voltage is $80 \mathrm{kV}$, we propose selecting a current of $250 \mathrm{~mA}$ or below or selecting a tube voltage of $100 \mathrm{kV}$ in the settings. When the objective is to both reduce exposure dose and ensure image quality, we propose scan conditions of $80 \mathrm{kV}$ at $200-250 \mathrm{~mA}$ or $100 \mathrm{kV}$. A tube voltage of $100 \mathrm{kV}$ also resulted in lower contrast images than those obtained with $80 \mathrm{kV}$. When the objective is only a morphological diagnosis such as in cases of osteogenesis imperfecta, though increasing the tube voltage may prevent 
any loss of diagnostic performance, it also causes an unavoidable increase in exposure dose; hence, both diagnostic performance and exposure must be considered in such cases. Ultimately, each facility makes their own decisions on scanning conditions and use the various findings collected in this article as a reference.

Running an MC simulation of a CT scan requires a bowtie filter and energy spectra. We estimated the bowtie filter shape (Fig. 4a) based on X-ray transmission using the measurement method recommended by ImPACT MC software. The energy spectra estimated from the measured half-value layer (Fig. 4b) showed an absorption edge at an energy close to that of the K-absorption edge [24, 25], which arises from estimating primary X-ray energy spectra using Klein-Nishina differential cross sections based on actual measurements of Compton scattered photons from the CT system that are collected with a cadmium telluride detector. Accordingly, MC simulations were also run on these energy spectra.

The exposure dose in normal fetal CT scans $\left(\mathrm{OEM}_{\mathrm{OFF}}\right)$ was highest on the anterior side (of the pregnant woman), followed by the posterior side, and then the lateral side (Figs. 5, 6). This difference in exposure dose is attributed to $\mathrm{X}$-ray absorption by the bed and differences in body thickness. $\mathrm{OEM}_{\mathrm{ON} \text {,front }}$ also reduced the dose absorbed by the anterior side and $\mathrm{OEM}_{\mathrm{ON} \text {,back }}$ reduced the dose absorbed by the posterior side (Figs. 5, 6). In both these situations, we had difficulty reducing the dose absorbed in the center of the axial section of the pregnant woman. In utero, the fetus is positioned with its head in the pelvic cavity (toward the center of the axial section) and its thoraco-abdominal region at the body surface pushing against the lower abdominal region of the pregnant woman. Consequently, OEM causes a greater reduction in $\mathrm{D}_{\mathrm{T}, \mathrm{R}}$ in the thoraco-abdominal region of the fetus than in the head and neck region (Figs. 5, 6). Given that $\mathrm{D}_{\mathrm{T}, \mathrm{R}}$ is affected by both the position of the fetus and the overlapping of $\mathrm{X}$-rays that occurs due to slice width and the number of slices along the body axis, OEM will not reduce the dose to specific organs. Furthermore, for all fetuses, the findings indicated that $\mathrm{D}_{\mathrm{T}, \mathrm{R}}$ tended to be highest in the breasts, lungs, stomach, colon, gonads, and red bone marrow. The highest of these was $\mathrm{D}_{\text {red marrow}}$, which was calculated as a weighted value according to the weight distribution of the red bone marrow and based on the evaluation method proposed by Nishizawa et al. [20]. Although $\mathrm{D}_{\text {red marrow }}$ was the highest (Patient F, OEM $\mathrm{OFF}_{1}: 1.86 \mathrm{mGy}$ ), the $\mathrm{D}_{\mathrm{T}, \mathrm{R}}$ during fetal CT scans was still acceptably lower than the dose received during abdominal CT scans (mean: $8 \mathrm{mGy}$, maximum: $49 \mathrm{mGy}$ ) or pelvic CT scans (mean: $25 \mathrm{mGy}$, maximum: $79 \mathrm{mGy}$ ) performed for image-based diagnosis of the pregnant mother [6]. If the fetal dose is evaluated on the basis of the $\mathrm{D}_{\text {red marrow }}$, then detailed informed consent will be needed for the CT scan, as the fetal dose exceeds
$1 \mathrm{mGy}$. However, as the fetal dose is $100 \mathrm{mGy}$ or less, the increased risk of prenatal death, deformity, or mental retardation is almost never large enough to be detectable above spontaneous incidence [6]. Methods for evaluating this type of exposure dose to the fetus and organs proposed thus far have used fundamental experiments in human phantoms [26, 27], MC methods in reference human digital phantoms [28], or simplified dose estimation methods [10, 29, 30]. In this study, fetus $\mathrm{D}_{T, R}$ was estimated in detail by MC simulation based on clinical images, and ED was calculated.

The ED to the fetus associated with a fetal CT scan was determined to be 5.1-7.2 $\mathrm{mSv}$. However, because the purpose of this study was to examine the effect of OEM on fetal CT scans, clinical cases that used scanning conditions with an unmodified X-ray output were excluded from the study. Among the cases we evaluated, $\mathrm{OEM}_{\mathrm{ON} \text {,front }}$ was extremely effective in Patients $\mathrm{B}$ and $\mathrm{C}$ (tube voltage, $80 \mathrm{kV}$; maximum tube current, $232 \mathrm{~mA}$ ), as there was only minor reduction in image quality in the $0^{\circ} \pm 90^{\circ}$ range. Fetal CT scans also cause unnecessary medical exposure to the pregnant woman. For this reason, we evaluated $\mathrm{OEM}_{\mathrm{ON}, \text { back }}$ as a means of maximally reducing the exposure dose to the pregnant woman. However, as there was only a limited reduction in $\mathrm{D}_{\mathrm{T}, \mathrm{R}}$ to the liver, bladder, and colon of the pregnant woman with $\mathrm{OEM}_{\mathrm{ON}, \text { back }}$ (Fig. 7), it would seem more advantageous to pursue obtaining advanced informed consent that allows preferential use of $\mathrm{OEM}_{\mathrm{ON}, \text { front }}$.

\section{Conclusion}

In this paper, we evaluated the utility of OEM in fetal CT scans from the standpoint of image quality and exposure dose to the pregnant mother and fetus. With proper understanding of the characteristics of OEM, it can serve as an effective tool for dose reduction in fetal CT scans. Similar to using OEM for exposure dose reduction to breasts and the lens of the eye, OEM should also be encouraged for fetal CT scans.

Acknowledgements We would like to thank Editage (www.edita ge.com) for English language editing.

Author contributions TH measured bowtie filter shape and air-kerma. SS evaluated image noise. YN run the MC simulation and evaluated doses with SS. YA and KM was a major contributor in writing the manuscript. All authors read and approved the final manuscript.

Funding This research was conducted with financial assistance from JSPS KAKENHI Grant Number JP 19K17152.

Code availability ImPACT MC Version 1.60 (CT imaging GmbH, Erlangen, Germany) MC simulation software. 


\section{Compliance with ethical standards}

Conflict of interest The authors declare that they have no conflict of interest.

Ethical approval This study was performed in accordance with the principles of the Declaration of Helsinki. Approval was granted by the Ethics Committee of Fujita Health University (February 19, 2019; HM18-433).

Informed consent Informed consent was obtained in the form of optout to notify or disclose information about the study and ensured that participants could refuse to partake or continue partaking in the study.

Open Access This article is licensed under a Creative Commons Attribution 4.0 International License, which permits use, sharing, adaptation, distribution and reproduction in any medium or format, as long as you give appropriate credit to the original author(s) and the source, provide a link to the Creative Commons licence, and indicate if changes were made. The images or other third party material in this article are included in the article's Creative Commons licence, unless indicated otherwise in a credit line to the material. If material is not included in the article's Creative Commons licence and your intended use is not permitted by statutory regulation or exceeds the permitted use, you will need to obtain permission directly from the copyright holder. To view a copy of this licence, visit http://creativecommons.org/licenses/by/4.0/.

\section{Appendix}

$D_{\text {redmarrow }}=\sum m d \times \frac{1}{M}$

where $m$ is the weight of the red bone marrow being measured, $\mathrm{d}$ is the dose measured in the red bone marrow, and $\mathrm{M}$ is the weight of all red bone marrow in the body [20]. Mineralized bone was also calculated with Eq. 6 using an exposure dose in the same locations.

\section{References}

1. Boric I, Prpić Vučković R (2017) Imaging in osteogenesis imperfecta. Paediatr Croat 61:122-128. https://doi.org/10.13112 /PC.2017.17

2. Minch CM, Kruse RW (1998) Osteogenesis imperfecta: a review of basic science and diagnosis. Orthopedics 21:558-567. https:// doi.org/10.3928/0147-7447-19980501-09

3. Sargar KM, Singh AK, Kao SC (2017) Imaging of skeletal disorders caused by fibroblast growth factor receptor gene mutations. Radiographics 37:1813-1830. https://doi.org/10.1148/rg.20171 70017

4. Dighe M, Figner C, Cheng E, Warren B, Dubinsky T (2008) Fetal skeletal dysplasia: an approach to diagnosis with illustrative cases. Radiographics 28:1061-1077. https://doi.org/10.1148/rg.28407 5122

5. Gaffney G, Manning N, Boyd PA, Rai V, Gould S, Chamberlain P (1998) Prenatal sonographic diagnosis of skeletal dysplasias: a report of the diagnostic and prognostic accuracy in 35 cases. Prenat Diagn 18:357-362
6. International Commission on Radiological Protection (2000) Pregnancy and Medical Radiation. Ann ICRP. 30(1). ICRP Publication no. 84.

7. Ota J, Yokota H, Takishima H, Takada A, Irie R, Suzuki Y, Nagashima T, Horikoshi T, Chida K, Masuda Y, Uno T (2019) Breast exposure reduction using organ-effective modulation on chest CT in Asian women. Eur J Radiol. https://doi.org/10.1016/j. ejrad.2019.108651

8. Akai H, Kiryu S, Shibata E, Maeda E, Sato J, Tomizawa N, Nojima M, Ohtomo K (2016) Reducing CT radiation exposure with organ effective modulation: a retrospective clinical study. Eur J Radiol 85:1569-1573. https://doi.org/10.1016/j.ejrad .2016 .06 .008

9. Taylor S, Litmanovich DE, Shahrzad M, Bankier AA, Gevenois PA, Tack D (2014) Organ-based tube current modulation: are women's breasts positioned in the reduced-dose zone? Radiology 274:260-266. https://doi.org/10.1148/radiol.14140694

10. Angel E, Wellnitz CV, Goodsitt MM, Yaghmai N, DeMarco JJ, Cagnon CH, Sayre JW, Cody DD, Stevens DM, An P, McCollough $\mathrm{CH}$, McNitt-Gray MR (2008) Radiation dose to the fetus for pregnant patients undergoing multidetector CT imaging: Monte Carlo simulations estimating fetal dose for a range of gestational age and patient size. Radiology 249:220-227. https://doi. org/10.1148/radiol.2491071665

11. Xie T, Poletti PA, Platon A, Becker CD, Zaidi H (2018) Assessment of CT dose to the fetus and pregnant female patient using patient-specific computational models. Eur Radiol 28:1054-1065. https://doi.org/10.1007/s00330-017-5000-z

12. Gu J, Xu XG, Caracappa PF, Liu B (2013) Fetal doses to pregnant patients from CT with tube current modulation calculated using Monte Carlo simulations and realistic phantoms. Radiat Prot Dosimetry 155:64-72. https://doi.org/10.1093/rpd/ncs312

13. ACR-SPR Practice parameter for imaging pregnant of potentially pregnant adolescents and women with ionizing radiation - revised 2018 resolution 39 (American College of Radiology). https:// www.acr.org/-/media/ACR/Files/Practice-Parameters/PregnantPts.pdf. Accessed 3 Apr 2020

14. Anam C, Haryanto F, Widita R, Arif R, Toyoda T, Dougherty G (2017) Scatter index measurement using a CT dose profiler. J Med Phys Biop 4:95-102

15. Hara T, Niwa S, Urikura A, Matsubara K, Hoshino T, Nishimaru E (2019) Assessment of longitudinal beam property and contrast uniformity for 256- and 320-row area detector computed tomography scanners in the $160-\mathrm{mm}$ nonhelical volume-acquisition mode. J Appl Clin Med Phys 20:164-170. https://doi.org/10.1002/ acm2.12670

16. Chen W, Kolditz D, Beister M, Bohle R, Kalender WA (2012) Fast on-site Monte Carlo tool for dose calculations in CT applications. Med Phys 39:2985-2996. https://doi.org/10.1118/1.4711748

17. Deak P, Van Straten M, Shrimpton PC, Zankl M, Kalender WA (2007) Validation of a Monte Carlo tool for patient-specific dose simulations in multi-slice computed tomography. Eur Radiol 18:759-772

18. Kobayashi M, Asada Y, Haba T, Matsunaga Y, Matsubara K, Minami K (2019) Optimisation of swallowing CT examination: dose reduction and image quality. Radiat Prot Dosimetry 185:421-431. https://doi.org/10.1093/rpd/ncz029

19. Tucker DM, Barnes GT, Chalraborty DP (1991) Semiempirical model for generating tungsten target X-ray spectra. Med Phys $18: 211-218$

20. Nishizawa K, Maruyama T, Takayama M, Iwai K, Furuya Y (1995) Estimation of effective dose from CT examination. Jpn J Radiol 55:763-768 (in Japanese)

21. International Commission on Radiological Protection. Adult Reference Computational Phantoms. Ann ICRP. 39 (2) 2009; ICRP Publication no. 110. 
22. International Commission on Radiological Protection. The 2007 Recommendations of the International Commission on Radiological Protection. Ann ICRP. 37 (2-4) 2007; ICRP Publication no. 103.

23. Takagi M, Kamiya M, Nagai K, Terada M (2018) Examination about the direction for uses of the radiation exposure reduction mechanism (organ effective modulation) in consideration of organ sensitivity. Jpn J Radiol 74:1406-1411. https://doi.org/10.6009/ jjrt.2018_JSRT_74.12.1406 (in Japanese)

24. Chen F, Chen P, Han Y, Pan J (2010) X-ray spectrum sampling technology in the CT projection simulation. Procedia Eng 7:106114. https://doi.org/10.1016/j.proeng.2010.11.016

25. Kasai Y, Nishihara S, Yuasa M, Kanoshige T, Matsuura T (2015) Investigation of the columnar carbon-scatter length for X-ray spectral measurement on 320-slice computed tomography. Jpn J Radiol 71:423-427. https://doi.org/10.6009/jjrt.2015_JSRT_71.5.423 (in Japanese

26. Kelaranta A, Kaasalainen T, Seuri R, Toroi P, Kortesniemi M (2015) Fetal radiation dose in computed tomography. Radiat Prot Dosimetry 165:226-230. https://doi.org/10.1093/rpd/ncv097

27. Matsunaga Y, Kawaguchi A, Kobayashi M, Suzuki S, Suzuki S, Chida K (2016) Dose evaluation for foetal computed tomography with a 320-row unit in wide-volume mode and an 80-row unit in helical scanning mode: a phantom study. Radiat Prot Dosimetry 168:523-530. https://doi.org/10.1093/rpd/ncv374

28. Matsunaga Y, Kawaguchi A, Kobayashi M, Suzuki S, Asada Y, Ito K, Chida K (2017) Fetal dose conversion factor for fetal computed tomography examinations: a mathematical phantom study. J Appl Clin Med Phys 18:330-335. https://doi.org/10.1002/acm2.12154

29. Felmlee JP, Gray JE, Leetzow ML, Price JC (1990) Estimated fetal radiation dose from multislice CT studies. AJR Am J Roentgenol 154:185-190

30. Ozbayrak M, Cavdar I, Seven M, Uslu L, Yeyin N, Tanqidizi H, Abuqbeitha M, Acikgoz AS, Tuten A, Demir M (2015) Determining and managing fetal radiation dose from diagnostic radiology procedures in Turkey. Korean J Radiol 15:1276-1282. https://doi. org/10.3348/kjr.2015.16.6.1276

Publisher's Note Springer Nature remains neutral with regard to jurisdictional claims in published maps and institutional affiliations. 